\title{
$\beta$-Conglycinin Reduces the Tight Junction Occludin and ZO-1 Expression in IPEC-J2
}

\author{
Yuan Zhao ${ }^{1,2}$, Guixin Qin ${ }^{1,2, *}$, Rui Han ${ }^{1}$, Jun Wang ${ }^{1}$, Xiaodong Zhang ${ }^{3}$ and Dandan Liu ${ }^{1}$ \\ 1 College of Animal Science and Technology, Jilin Agricultural University, Changchun 130118, \\ China; E-Mails: zhaoyuan4CL52@126.com (Y.Z.); hanrui0409@163.com (R.H.); \\ wangjun4169@126.com (J.W.); ddliu19880922@163.com (D.L.)
}

2 Key Laboratory of Animal Production, Product Quality and Security, Ministry of Education, Jilin Agricultural University, Changchun 130118, China

3 Key Laboratory of Zoonosis Research, Ministry of Education, Institute of Zoonosis, College of Veterinary Medicine, Jilin University, Changchun 130062, China;

E-Mail: zhang_xd@jlu.edu.cn

* Author to whom correspondence should be addressed; E-Mail: qgx@jlau.edu.cn; Tel./Fax: +86-431-8453-3506.

Received: 24 November 2013; in revised form: 12 January 2014 / Accepted: 20 January 2014 / Published: 27 January 2014

\begin{abstract}
Soybean allergy presents a health threat to humans and animals. The mechanism by which food/feed allergen $\beta$-conglycinin injures the intestinal barrier has not been well understood. In this study, the changes of epithelial permeability, integrity, metabolic activity, the tight junction (TJ) distribution and expression induced by $\beta$-conglycinin were evaluated using IPEC-J2 model. The results showed a significant decrease of trans-epithelial electrical resistance (TEER) $(p<0.001)$ and metabolic activity $(p<0.001)$ and a remarkable increase of alkaline phosphatase (AP) activity $(p<0.001)$ in a dose-dependent manner. The expression levels of tight junction occludin and ZO-1 were decreased $(p<0.05)$. The reduced fluorescence of targets and change of cellular morphology were recorded. The tight junction occludin and ZO-1 mRNA expression linearly declined with increasing $\beta$-conglycinin $(p<0.001)$.
\end{abstract}

Keywords: $\beta$-conglycinin; intestinal barrier; tight junction; food allergen; IPEC-J2 


\section{Introduction}

The increasing consumption of various soybean products owing to their high nutritional value has lead to a rise in the incidence of soybean allergies [1]. Soybean $\beta$-conglycinin, the major food/feed allergen, is recognized by IgE antibodies present in soybean-allergic humans [2,3] and animals [4].

The intestinal mucosa represents a crucial border between the organism and its environment. The large contact surface allows efficient nutrient absorption, acts as an important barrier for pathogens and toxins, and participates in the innate immune response $[5,6]$. As recently reported, $\beta$-conglycinin may produce three major enzyme-hydrolyzed peptides (the molecular weight of 52, 30 and $25 \mathrm{kD}$, respectively) with the intact $\mathrm{IgG}$ and $\mathrm{IgE}$ binding epitopes after digestion by continuous pepsin and trypsin [7]. Both digested and undigested $\beta$-conglycinin can transit through the stomach and small intestine [8-11], and be absorbed in immunoreactive form by the gut epithelium, facilitating the exposition of these allergens to the immune system, which would consequently elicit an allergic response in a sensitized individual $[12,13]$.

Piglets easily suffer from soybean-induced allergy, so the presence of allergenic components including intact $\beta$-conglycinin and its enzyme-hydrolyzed peptides greatly restricts their use in neonatal and weanling pigs. Soybean allergies usually cause inflammatory disorders in the small intestine, characterized by villous atrophy and hyperplasia in the crypt, as well as accelerated enterocyte proliferation, apoptosis and migration [14-18]. However, so far, there have been few studies into the effects of $\beta$-conglycinin on the intestinal barrier permeability of piglets.

The intestinal porcine epithelial cells originated from jejunum (IPEC-J2) retained most of their original epithelial nature [5]. So we opted for the use of an IPEC-J2 that would maximally resemble the in vivo situation. Meanwhile, it could also give some related hints for soybean-allergic patients due to porcine physiological and immunological similarity to human beings [19,20]. In this study, the epithelial permeability, integrity, metabolic activity, tight junction (TJ) distribution and expression in IPEC-J2 respectively treated with $\beta$-conglycinin were determined, which are essential criteria to explore the mechanism of soybean-induced allergy.

\section{Results}

\subsection{TEER}

As shown from Figure 1, 0-3 mg/mL $\beta$-conglycinin decreased the TEER after 24, 48 and $72 \mathrm{~h}$ incubation in a dose-dependent manner. The negative linear correlation existed between TEER and $\beta$-conglycinin ( $p<0.001, R^{2}=0.919$ ) levels at $24 \mathrm{~h}$. The highest concentration of $\beta$-conglycinin $(3 \mathrm{mg} / \mathrm{mL}$ ) reduced the TEER to $67 \%$ of the control after $24 \mathrm{~h}$, respectively. The maximal reduction of TEER (versus control) was $38 \%$ after $72 \mathrm{~h}$ incubation, respectively.

\subsection{Cellular Metabolic Activity Detected by MTT Assay}

A significant linear reduction of cellular metabolic activity was detected after application of $0.5-3 \mathrm{mg} / \mathrm{mL} \beta$-conglycinin $\left(R^{2}=0.862, p<0.001\right)$ at $24 \mathrm{~h}$ (Figure 2$)$. The highest $\beta$-conglycinin 
concentration $(3 \mathrm{mg} / \mathrm{mL})$ reduced the metabolic activity to the minimum $78 \%$ (versus control) after $72 \mathrm{~h}$ incubation, respectively.

Figure 1. Trans-epithelial electrical resistance (TEER) of intestinal porcine epithelial cells originated from jejunum (IPEC-J2) cells after 24, 48 and $72 \mathrm{~h}$ incubation of $\beta$-conglycinin. Each bar represents four independent experiments performed in triplicates \pm SD. a, b, c, d, $e, f$ each represent two groups for different concentrations which are statistically different from each other.

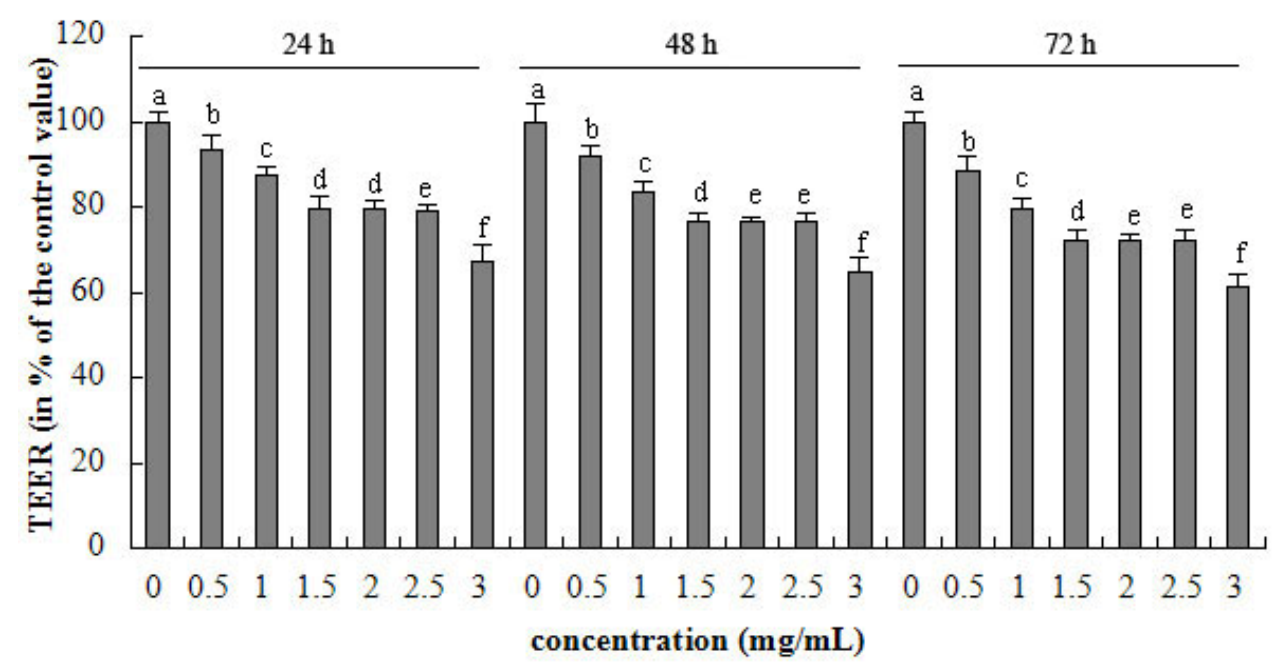

Figure 2. Metabolic activity of IPEC-J2 cells after 24, 48 and $72 \mathrm{~h}$ incubation of $\beta$-conglycinin measured by MTT assay. Each bar represents four independent experiments performed in triplicates \pm SD. $a, b, c, d$, e, f each represent two groups for different concentrations which are statistically different from each other.

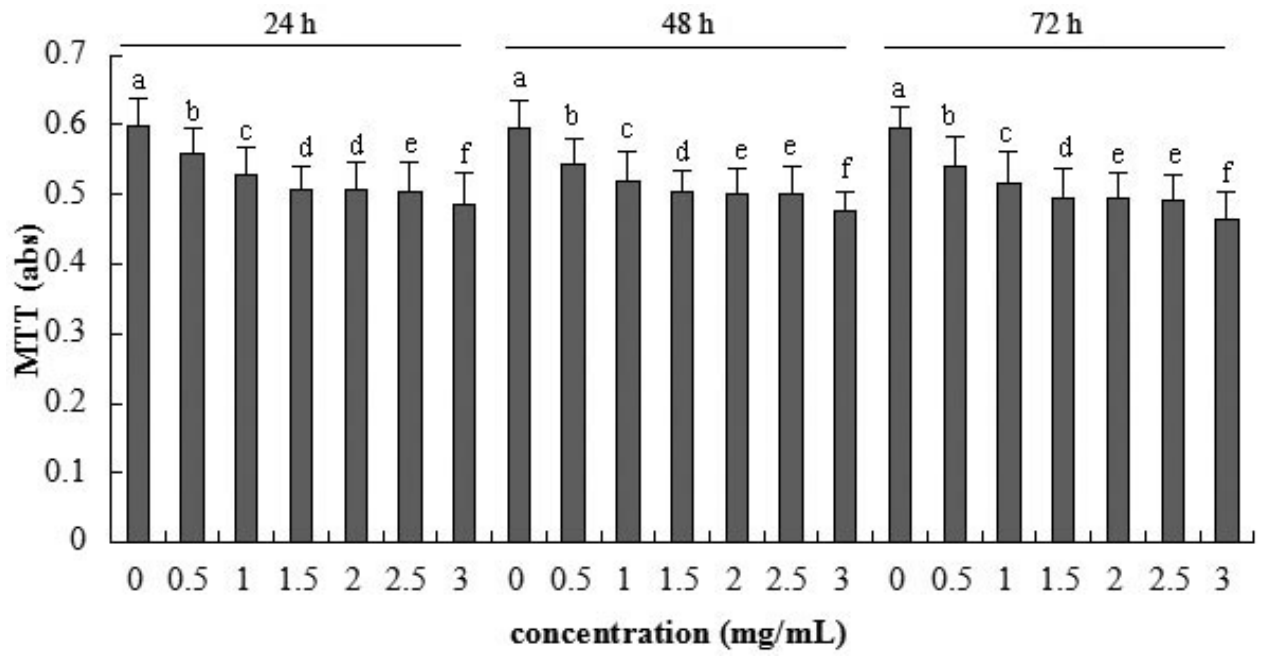

\subsection{Cellular Integrity Assessed by AP Activity}

Detection of AP activity as a marker for enterocyte differentiation [21] showed a remarkable increase for $0.5 \mathrm{mg} / \mathrm{mL} \beta$-conglycinin at $72 \mathrm{~h}$ (Figure 3). The AP activity had a positive linear relationship with the $\beta$-conglycinin levels $\left(R^{2}=0.603, p<0.001\right)$. 
Figure 3. Alkaline phosphatase activity of IPEC-J2 cells after $72 \mathrm{~h}$ incubation of $\beta$-conglycinin. Each bar represents four independent experiments performed in triplicates \pm SD. a, b, c, cd, d, e each represent two groups for different concentrations which are statistically different from each other.

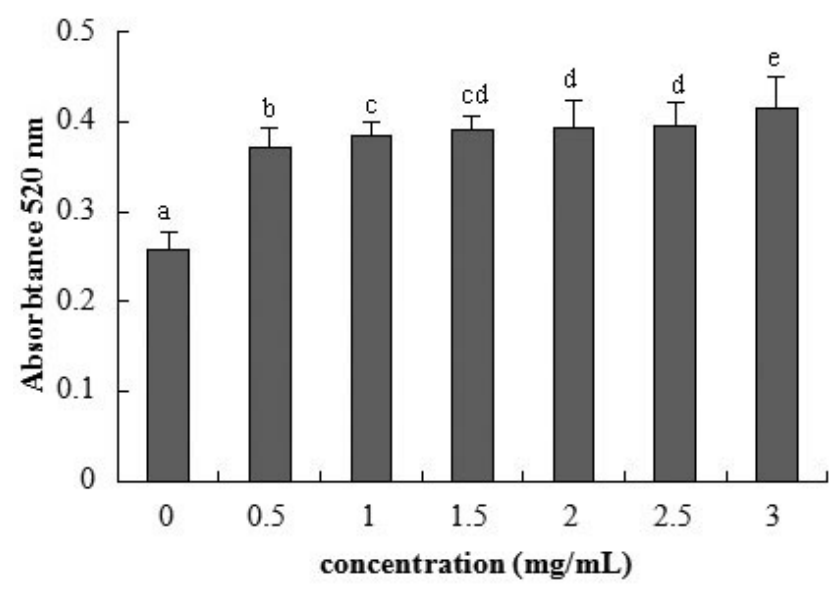

\subsection{Tight Junction Distribution and Expression}

The tight junction proteins (occludin and zonula occluden (ZO)-1) were located at the cell-cell contact regions, as shown in Figure 4. After treatment with $\beta$-conglycinin, the cellular morphology was altered, and the cellular junction location was obscure. The staining intensity of occludin and ZO-1 clearly decreased compared with the control. The protein expression of occludin and ZO-1 were clearly reduced by $46 \%$ and $15 \%$ when analyzed by western-blot (Figure 5), respectively $(p<0.05)$.

Figure 4. Tight junction proteins distribution of IPEC-J2 cells after $24 \mathrm{~h}$ incubation of $\beta$-conglycinin. Representative images of immunofluorescence staining (magnification $200 \times$ ) are shown.

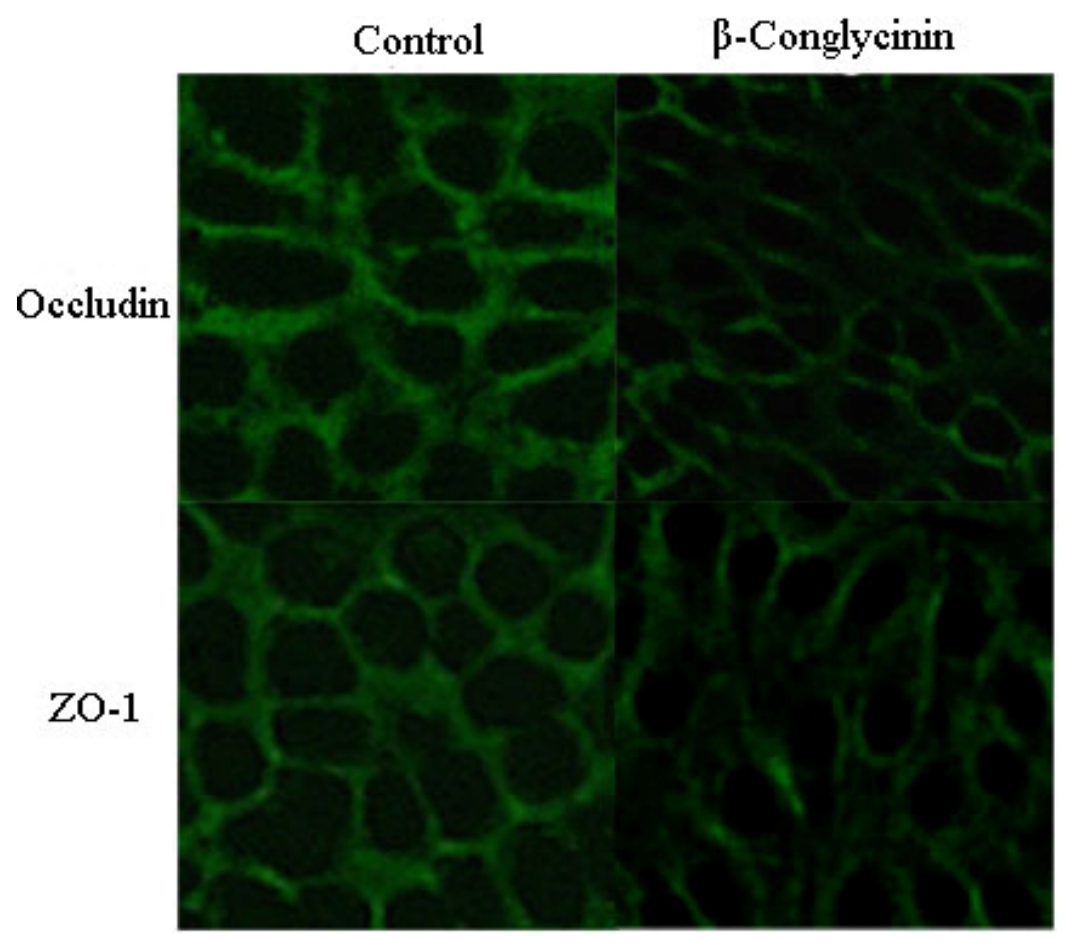


Figure 5. Western blot of tight junction proteins of IPEC-J2 cells after $24 \mathrm{~h}$ incubation of $\beta$-conglycinin. The $\beta$-actin is housekeeping protein. Representative western blots from four independent experiments are shown.

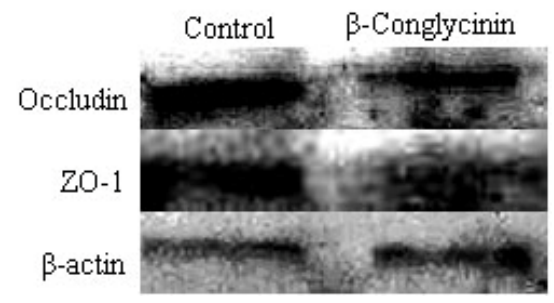

\subsection{Tight Junction mRNA Expression}

Tight junction occludin or ZO-1 mRNA expression was assessed after $24 \mathrm{~h}$ exposure to $\beta$-conglycinin of different levels. The tight junction mRNA expression tended to linearly decline with increasing $\beta$-conglycinin (occludin: $R^{2}=0.941, p<0.001$; ZO-1, $R^{2}=0.956, p<0.001$ ) from $0.5-3 \mathrm{mg} / \mathrm{mL}$ (Figures 6 and 7). After $24 \mathrm{~h}$ incubation, the maximal reduction of occludin (versus control) and ZO-1 (versus control) was $57 \%$ and $59 \%$ for $\beta$-conglycinin.

Figure 6. Occludin relative mRNA expression of IPEC-J2 cells after $24 \mathrm{~h}$ incubation of $\beta$-conglycinin. Each bar represents four independent experiments performed in triplicates \pm SD. a, b, c, d, e, f, g each represent two groups for different concentrations which are statistically different from each other.

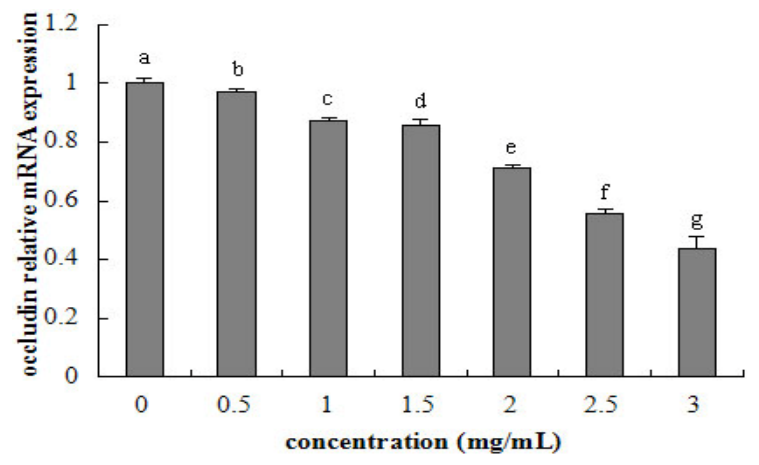

Figure 7. ZO-1 relative mRNA expression of IPEC-J2 cells after $24 \mathrm{~h}$ incubation of $\beta$-conglycinin. Each bar represents four independent experiments performed in triplicates \pm SD. a, b, c, d, e, f, g each represent two groups for different concentrations which are statistically different from each other.

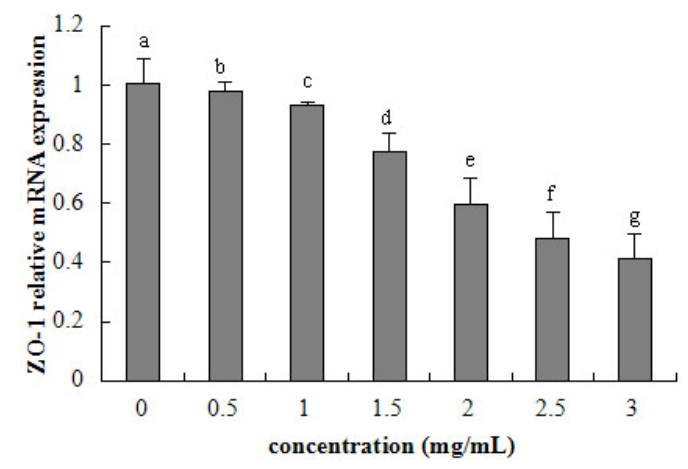




\section{Discussion}

Food allergy is an increasing clinical problem and has been estimated to affect $5 \%-6 \%$ of children and $3 \%-4 \%$ of the adult population [22,23]. Egg ovalbumin, cow milk, wheat, peanuts, and soybean allergic proteins are commonly known as food allergens [24]. The intestinal epithelium has not only an absorption function for dietary factors but also a barrier function to restrict the permeation of noxious substances. Physiologically, most dietary proteins are digested to small peptides or amino acids, which are then absorbed into enterocytes. A small amount of intact allergic protein may be endocytosed into epithelial cells for degradation and lose their antigenic properties [25-28]. In food allergy, IgE/CD23 mediate antigen transcellular transport in the epithelial cells prior to mast cell activation, or it crosses epithelial cells through the paracellular pathway and transcellular pathway after the release of mast cell mediators [29,30].

Food allergy such as induced by ovalbumin (OVA) could increase the intestinal permeability [31-34]. TEER is used as a parameter of epithelial barrier function, which indicates variation of integrity and permeability of the cell monolayer $[35,36]$. The present study displays that $\beta$-conglycinin induced low TEER of intestinal epithelium. This means that the soybean allergen can enhance the epithelial permeability. TEER measure is usual in toxicology but rare in food allergy. Results regarding the wheat germ agglutinin toxin are accordance with our results [37].

The MTT assay is a standard method for the detection of metabolic activity in cell culture, which indirectly demonstrates the damage of membrane function. The present data show that $\beta$-conglycinin reduces the cellular metabolic activity in a dose-dependent manner, suggesting the reduction of cellular activity, which is similar to Xu et al. (2010) [38] using the mouse intestinal epithelial cells as model. Transient hypersensitivity to soybean antigens could lead to villus atrophy, crypt hypertrophy [14-16,39]. In addition, $\beta$-conglycinin may accelerate the enterocyte apoptosis and the relative enterocyte migration rate for piglets in our previous study [18]. The above literature provides evidence that $\beta$-conglycinin could induce the low enterocyte activity.

Intestinal AP has an essential function in maintaining epithelial integrity, whose loss may increase the permeability to inflammation and sepsis [40,41]. In our present study, the experimental results show that the AP activity showed a remarkable increase, so $\beta$-conglycinin has significant negative effects on the cellular integrity. This corresponds to the changed epithelial permeability.

TJ, a major mode of cell-to-cell adhesion, is a key determinant of intestinal barrier function preventing bacteria, endotoxin and toxicity macromolecule from crossing an epithelial sheet between adjacent cells. It is organized by specific interactions between various intracellular proteins (ZO-1, ZO-2, ZO-3, MUPP-1) and transmembrane proteins (occludin, claudin, and junctional adhesion molecules) [42]. The reduction of occludin [43] and ZO-1 [44] can enhance the epithelial permeability in a number of cell systems. After a challenge with food allergen, the increased permeability has been shown to initially amplify allergen ingestion and translocation through the transcellular route, and subsequently enlarge the paracellular permeability associated with a disruption of TJ after sensitization depending on activated mast cells $[29,45]$. However, literature regarding soybean allergen and epithelial integrity and permeability are rare. It has been found in our study that the $\beta$-conglycinin decreased occludin and ZO-1 in IPEC-J2, which also demonstrates that the soybean $\beta$-conglycinin destroys the epithelial barrier owing to the reduced TJ expression. 
The regression analysis suggests that $\beta$-conglycinin has a linear relationship with the cellular permeability, metabolic activity, integrity, and TJ gene expression. This means that the increasing soybean allergens induce the tight junction to loosen, and then augment the epithelial permeability. Moreover, from observation, it seems that indexes of the current study change seriously with the extension of incubation time.

\section{Methods and Materials}

\subsection{Preparation of $\beta$-Conglycinin}

$\beta$-Conglycinin was isolated from defatted soy flour by the method of Setsuko et al. (1987) [46]. The globulins sample contained over $95 \% \beta$-conglycinin determined by the Kjeldahl method and SDS-PAGE analysis.

\subsection{Cells and Culture Conditions}

The porcine intestinal epithelial cells from jejunum (IPEC-J2) were kindly donated by Guoyao $\mathrm{Wu}$ of China Agricultural University. The IPEC-J2 were seeded in cell culture flasks and cultured in DMEM/F12 medium (Gibco, Carlsbad, NM, USA), supplemented with $10 \%$ fetal bovine serum (FBS, Gibco, Carlsbad, NM, USA), 1\% Penicillin-Streptomycin (Sigma, St. Louis, MO, USA), and $1 \%$ glutamine (Amersco, Solon, Tucson, AZ, USA) at $37{ }^{\circ} \mathrm{C}$ in a humidified atmosphere of $5 \%$ $\mathrm{CO}_{2}$ (Selecta, Barcelona, Spain). The culture medium was changed every other day.

\subsection{Trans-Epithelial Electrical Resistance (TEER) Measurement}

IPEC-J2 were seeded on the millicell membrance (Millipore, Billerica, MA, USA, $0.3 \mu \mathrm{m}$ pore size) cell culture inserts (Costar, Corning Inc., New York, NY, USA) at a density of $5 \times 10^{4} / \mathrm{cm}^{2}$. When monolayer of cells was completely differentiated, cells were treated with $0,0.5,1.0,1.5,2.0,2.5$, $3.0 \mathrm{mg} / \mathrm{mL}$ of $\beta$-conglycinin. The TEER was measured using the millicell-ERS resistance system (Millipore, Billerica, MA, USA) after incubation for 24, 48, and $72 \mathrm{~h}$, respectively.

\subsection{MTT Assay}

Metabolic activity was measured by MTT assay. IPEC-J2 were then treated with $0,0.5,1.0,1.5$, $2.0,2.5,3.0 \mathrm{mg} / \mathrm{mL} \beta$-conglycinin for 24,48 , and $72 \mathrm{~h}$, respectively. Exactly $20 \mu \mathrm{L}$ of MTT solutions (Sigma, Aldrich Inc., St. Louis, MO, USA) was added to each well and incubated for $4 \mathrm{~h}$ at $37^{\circ} \mathrm{C}$. The mixture reaction was carefully taken out and $150 \mu \mathrm{L}$ dimethyl sulfoxide (DMSO, Solarbio, Shanghai, China) was added to each well, which was allowed to stand 10 min to allow it to completely mix. After the crystals were fully dissolved, the optical density was measured at $570 \mathrm{~nm}$ by Microplate Reader (Bio-Rad, Hercules, CA, USA).

\subsection{Alkaline Phosphatase Activity Assay}

Cellular membrane integrity was assessed by measurement of alkaline phosphatase (AP) activity in the supernatant. Cells were grown in a 96-well microplate and treated with 0, 0.5, 1.0, 1.5, 2.0, 2.5, 
$3.0 \mathrm{mg} / \mathrm{mL} \beta$-conglycinin for $72 \mathrm{~h}$, respectively. The AP activity of the incubation medium was measured by the AP Test kit (Jiancheng, Nanjing, China).

\subsection{Analysis of Tight Junction Proteins Structure by Immunofluorescence}

IPEC-J2, grown on cover glass within six well plates (Nest, Beijing, China) for complete confluence, were treated with $0.5 \mathrm{mg} / \mathrm{mL} \beta$-conglycinin media for $24 \mathrm{~h}$. After rinsing in PBS three times, samples were fixed with cold acetone for $15 \mathrm{~min}$ at room temperature. Next, cells were permeabilized with 0.5\% Triton X-100 for $5 \mathrm{~min}$ and blocked with 5\% Bovine Serum Albumin (BSA) for $30 \mathrm{~min}$ at $37{ }^{\circ} \mathrm{C}$. After washing, samples were incubated with rabbit-anti-occludin or rabbit-anti-ZO-1 (diluted 1:100 or 1:100 in $1 \%$ of BSA respectively, Bios, Beijing, China) as the primary antibody for $30 \mathrm{~min}$ at $37^{\circ} \mathrm{C}$ then with FITC-conjugated goat-anti-rabbit (diluted 1:50, CWBIO, Beijing, China) as the second antibody for $2 \mathrm{~h}$ at room temperature. The views for each sample were captured using laser scanning confocal microscope (Nikon, Tokyo, Japan) and representative images were presented.

\subsection{Western Blot Analysis}

IPEC seeded in cell culture flasks were treated with $0.5 \mathrm{mg} / \mathrm{mL} \beta$-conglycinin media for $24 \mathrm{~h}$, then cells were washed with PBS $(0.01 \mathrm{M})$. Every flask of samples was lysed on ice with a $500 \mu \mathrm{L}$ cell lysis buffer (20 mM Tris-HCL pH 8.0, 5 mM EDTA and 1\% Triton X-100) and supplemented with protease inhibitors (Cat. 539134, Merck, Darmstadt, Germany) for $30 \mathrm{~min}$. Sample collections were sonicated three times for $20 \mathrm{~s}$ and centrifuged at $10,000 \times \mathrm{g}$ for $30 \mathrm{~min}$ at $4{ }^{\circ} \mathrm{C}$. Protein quantification of supernatant was determined by method of BCA kit (Thermo, Waltham, MA, USA).

Exactly $12 \mu \mathrm{g}$ of cell total proteins extraction was separated by SDS-PAGE and transferred onto PVDF membranes. The rabbit anti-occludin, rabbit anti-ZO-1 or rabbit anti- $\beta$-actin (Bios, Beijing, China) antibodies were used as the primary antibody. The horseradish peroxidase-conjugated anti-rabbilt IgG (diluted 1:3000, Tianjin Sungene Biotech Co., Tianjin, China) was incubated as the second antibody. The Luminata Crescendo Western HRP Substrate (Millipore, Billerica, MA, USA) was applied for chemiluminescent detection using tabletting and autoradiographic film (Kodak, Xiamen, China). Grey levels were estimated using Quantity One software-4.6.2 (Basic) (Bio-Rad, Hercules, CA, USA). Western blot band density was compared to $\beta$-actin in each lane as a loading control.

\subsection{RNA Extraction}

The IPEC-J2 was stimulated with varying concentrations of $\beta$-conglycinin $(0,0.5,1,1.5,2,2.5$, $3.0 \mathrm{mg} / \mathrm{mL}$ ) for $24 \mathrm{~h}$. Then the cells were rinsed twice with phosphate-buffered saline (PBS) without $\mathrm{Ca}^{2+}$ and $\mathrm{Mg}^{2+}$, harvested, centrifuged, and subjected to RNA extraction procedure.

Total cellular RNA was extracted from IPEC-J2 with E.Z.N.A. Total RNA Kit II (Omega, Doraville, GA, USA) according to the manufacturer's instructions. To prevent DNA contamination, DNase digestion was performed with RNase-free DNase. The Purified RNA extracts were stored at $-80{ }^{\circ} \mathrm{C}$ in RNase, DNase-free water (Takara, Otsu, Japan) until use. The concentration and purity of RNA extracts was determined using the absorbance at 260 and $280 \mathrm{~nm}$ in a spectrophotometer (Beckmandu-800, Fullerton, CA, USA). The samples with the ratio $260 \mathrm{~nm} / 280 \mathrm{~nm}$ between 1.9 and 
2.1 were further evaluated for their quality. The integrity of RNA was determined on $1 \%$ agarose gels and visualization of the $28 \mathrm{~S}$ and $18 \mathrm{~S}$ ribosomal RNA.

\subsection{Reverse Transcription}

Reverse transcription was performed using the High Capacity cDNA Reverse Transcription Kits (Applied Biosystems, Foster City, CA, USA). The reverse transcription was carried out in a $20 \mu \mathrm{L}$ final volume that included $2 \mu \mathrm{L} \mathrm{10 \times RT} \mathrm{Buffer,} 0.8 \mu \mathrm{L} 25 \times \mathrm{dNTP}$ Mix $(100 \mathrm{mM}), 2 \mu \mathrm{L} 10 \times \mathrm{RT}$ Random Primers, $1 \mu \mathrm{L}$ MultiScribe ${ }^{\mathrm{TM}}$ Reverse Transcriptase (Applied Biosystems, Foster City, CA, USA), $2 \mu \mathrm{g}$ RNA template, and Nuclease-free $\mathrm{H}_{2} \mathrm{O}$ to complete the final volume. The reserve transcription mix was incubated at $25{ }^{\circ} \mathrm{C}$ for $10 \mathrm{~min}$, heated to $37{ }^{\circ} \mathrm{C}$ for $120 \mathrm{~min}$, and finally inactivated at $85^{\circ} \mathrm{C}$ for $5 \mathrm{~min}$. The resultant cDNA was stored at $-80^{\circ} \mathrm{C}$ until use.

\subsection{Real-Time Quantitative PCR Analysis}

The real-time quantitative PCR was carried out using a StepOne Plus real-time PCR system (Applied Biosystems, Foster City, CA, USA). TaqMan Gene Expression Master Mix was used according to manufacturer's specifications (Applied Biosystems, Foster City, CA, USA). Primer and probe sets for target genes were prevalidated in TaqMan Gene Expression Assay kits (ABI): (ZO-1 Assay ID: Ss03373514; Occludin Assay ID: Ss03377507; $\beta$-actin Assay ID: Ss03376081). The PCR reaction was carried out in 96-well reaction plates with $10 \mu \mathrm{L}$ TaqMan Gene Expression Master Mix (2×), $1 \mu \mathrm{L}$ TaqMan Gene Expression Assay (20×), $2 \mu \mathrm{L}$ cDNA template and $7 \mu \mathrm{L}$ Nuclease-free $\mathrm{H}_{2} \mathrm{O}$. The 40 thermal cycles of $2 \mathrm{~min}$ at $50{ }^{\circ} \mathrm{C}, 10 \mathrm{~min}$ at $95{ }^{\circ} \mathrm{C}, 15 \mathrm{~s}$ at $95{ }^{\circ} \mathrm{C}$ and $1 \mathrm{~min}$ at $60{ }^{\circ} \mathrm{C}$ were utilized according to manufacturer recommendations.

Relative quantification of target genes was calculated using the $2^{-\Delta \Delta C t}$ method. Target gene expression was normalized to $\beta$-actin messenger RNA (mRNA) levels.

\subsection{Statistical Analysis}

Data of relative gene expression were analyzed using the general linear model procedure of Statistical Package for Social Sciences version 11.5 (SPSS Inc., Chicago, IL, USA). Differences among means were tested using Duncan's multiple range tests. Linear regression with calculation of the correlation factor $(r)$ was used for jointly distribution variables. Statements of statistical significance were based upon $p \leq 0.05$.

\section{Conclusion}

The altered $\mathrm{TJ}$ expression induced by $\beta$-conglycinin gives rise to the barrier dysfunction of intestinal epithelium.

\section{Acknowledgments}

This work was financially supported by the National Natural Science Foundation of China (No. 31101719) and the Scientific Research Foundation for Young Scholar of Jilin Science \& Technology Department of China (No. 201201098). 


\section{Conflicts of Interest}

The authors declare no conflict of interest.

\section{References}

1. Friedman, M.; Brandon, D.L. Nutritional and health benefits of soy proteins. J. Agric. Food Chem. 2001, 49, 1069-1086.

2. Ogawa, T.; Bando, N.; Tsuji, H.; Nishikawa, K.; Kitamura, K. Alpha-subunit of $\beta$-conglycinin, an allergenic protein recognized by $\operatorname{IgE}$ antibodies of soybean-sensitive patients with atopic-dermatitis. Biosci. Biotechnol. Biochem. 1995, 59, 831-833.

3. Krishnan, H.B.; Kim W.S.; Jang, S.; Kerley, M.S. All three subunits of soybean $\beta$-conglycinin are potential food allergens. J. Agric. Food Chem. 2009, 57, 938-943.

4. Hao, Y.; Zhan, Z.F.; Guo, P.F.; Piao, X.S.; Li, D.F. Soybean $\beta$-conglycinin-induced gut hypersensitivity reaction in a piglet model. Arch. Anim. Nutr. 2009, 63, 188-202.

5. Mariani, V.; Palermo, S.; Fiorentini, S.; Lanubile, A.; Giuffra, E. Gene expression study of two widely used pig intestinal epithelial cell lines: IPEC-J2 and IPI-2I. Vet. Immunol. Immunopathol. 2009, 131, 278-284.

6. Pitman, R.S.; Blumberg, R.S. First line of defense: The role of the intestinal epithelium as an active component of the mucosal immune system. J. Gastroenterol. 2000, 35, 805-814.

7. Zheng, S.G. The Identification of Potential Allergenic Subunits and Epitope-containing Peptide Fragments in Soybean Protein Glycinin and $\beta$-Conglycinin. Ph.D. Thesis, Jilin Agricultural University, Changchun, China, 2009.

8. Adachi, A.; Horikawa, T.; Shimizu, H.; Sarayama, Y.; Ogawa, T.; Sjolander, S.; Tanaka, A.; Moriyama, T. Soybean $\beta$-conglycinin as the main allergen in a patient with food-dependent exercise-induced anaphylaxis by tofu: Food processing alters pepsin resistance. Clin. Exp. Allergy 2009, 39, 167-173.

9. Lallès, J.P.; Tukur, H.M.; Salgado, P.; Mills, C.E.N.; Morgan, M.R.A.; Quillien, L.; Levieux, D.; Toullec, R. Immunochemical studies on gastric and intestinal digestion of soybean glycinin and $\beta$-conglycinin in vivo. J. Agric. Food Chem. 1999, 47, 2797-2806.

10. Wang, T.; Qin, G.X.; Zhao, Y.; Sun, Z.W. Comparative study on the stability of soybean (Glycine max) $\beta$-conglycinin in vivo. Food Agric. Immunol. 2009, 20, 295-304.

11. Zhao, Y.; Qin, G.X.; Sun, Z.W.; Zhang, B.; Wang, T. Stability and immunoreactivity of glycinin and $\beta$-conglycinin to hydrolysis in vitro. Food Agric. Immunol. 2010b, 21, 253-263.

12. Astwood, J.D.; Leach, J.N.; Fuchs, R.L. Stability of food allergens to digestion in vitro. Nat. Biotechnol. 1996, 14, 1269-1273.

13. Moreno, F.J.; Clemente, A. 2S albumin storage proteins: What makes them food allergens? Open Biochem. J. 2008, 2, 16-28.

14. Dunsford, B.R.; Knabe, D.A.; Hanesly, W.E. Effect of dietary soybean meal on the microscopic anatomy of the small intestine in the early weaned pigs. J. Anim. Sci. 1989, 67, 1855-1863.

15. Li, D.; Nelssen, J.L.; Reddy, P.G.; Belcha, F.; Hancock, J.D.; Allee, G.L.; Goodband, R.D. Transient hypersensitivity to soybean meal in the early-weaned pig. J. Anim. Sci. 1990, 68, 1790-1799. 
16. Qin, G.X.; Xu, L.M.; Jiang, H.L.; van der Poel, A.F.B.; Bosch, M.W.; Verstegen, M.W.A. The effect of Chinese and Argentine soybeans on nutrient digestibility and organ morphology in Landrace and Chinese Min pigs. Asian Aust. J. Anim. Sci. 2002, 15, 555-564.

17. Qiao, S.; Li, D.; Jiang, J.; Zhou, H.; Li, J.; Thacker, P. Effects of moist extruded full-fat soybeans on Gut morphology and mucosal cell turnover time of weanling pigs. Asian Aust. J. Anim. Sci. 2003, 16, 63-69.

18. Zhao, Y.; Qin, G.X.; Sun, Z.W.; Zhang, B.; Wang, T. Effects of glycinin and $\beta$-conglycinin on enterocyte apoptosis, proliferation and migration of piglets. Food Agric. Immunol. 2010, 21, 209-218.

19. Miller, E.R.; Ullrey, D.E. The pig as a model for human nutrition. Annu. Rev. Nutr. 1987, 7, 361-382.

20. Khatri, M.; Dwivedi, V.; Krakowka, S.; Manickam, C.; Ali, A.; Wang, L.; Qin, Z.M.; Renukaradhya, G.J.; Lee, C.W. Swine influenza H1N1 virus induces acute inflammatory Immune responses in pig lungs: A potential animal model for human $\mathrm{H} 1 \mathrm{~N} 1$ influenza virus. J. Virol. 2010, 84, 11210-11218.

21. Hinnebusch, B.F.; Siddique, W.; Henderson, W.; Malo, M.S.; Zhang, W.; Athaide, C.P.; Abedrapo, M.A.; Chen, X.; Yang, V.W.; Hodin, R.A. Enterocyte differentiation marker intestinal alkaline phosphatase is a target gene of the gut-enriched Krüppel-like factor. Am. J. Physiol. Gastrointest. Liver Physiol. 2004, 286, G23-G30.

22. Sampson, H.A. Allergy clinical immunology disorders. J. Allergy Clin. Immunol. 1999, 103, 717-728.

23. Venter, C.; Pereira, B.; Voigt, K.; Grundy, J.; Clayton, C.B.; Higgins, B.; Arshad, S.H.; Dean, T. Prevalence and cumulative incidence of food hypersensitivity in the first 3 years of life. Allergy 2008, 6, 354-359.

24. Tanabe, S. Epitope peptides and immunotherapy. Curr. Protein Pept. Sci. 2007, 8, 109-118.

25. Heyman, M.; Ducroc, R.; Desjeux, J.F.; Morgat, J.L. Horseradish peroxidase transport across adult rabbit jejunum in vitro. Am. J. Physiol. 1982, 242, 558-564.

26. Fujita, M.; Reinhart, F.; Neutra, M. Convergence of apical and basolateral endocytic pathways at apical late endosomes in absorptive cells of suckling rat ileum in vivo. J. Cell Sci. 1990, 97, 385-394.

27. Laiping, S.A.; Pelton-Henrion, K.; Small, G.; Becker, K.; Oei, E.; Tyorkin, M.; Sperber, K.; Mayer, L. Antigen uptake and trafficking in human intestinal epithelial cells. Dig. Dis. Sci. 2000, $45,1451-1461$.

28. Yu, L.C.H. The epithelial gatekeeper against food allergy. Pediatr. Neonatol. 2009, 50, 247-254.

29. Berin, M.C.; Kiliaan, A.J.; Yang, P.C.; Groot, J.A.; Kitamura, Y.; Perdue, M.H. The influence of mast cells on pathways of transepithelial antigen transport in rat intestine. J. Immunol. 1998, 161, 2561-2566.

30. Yu, L.C.H.; Yang, P.C.; Berin, M.C.; Di Leo, V.; Conrad, D.H.; McKay, D.M.; Satoskar, A.R.; Perdue, M.H. Enhanced transepithelial antigen transport in intestine of allergic mice is mediated by IgE/CD23 and regulated by interleukin-4. Gastroenterology 2001, 121, 370-381.

31. André, C.; André, F.; Colin, N.; Cavagna, S. Measurement of intestinal permeability to mannitol and lactulose as a means of diagnosing food allergy and evaluating therapeutic effectiveness of sodium cromoglycate. Ann. Allergy 1987, 59, 127-130.

32. Ventura, M.T.; Polimeno, L.; Amoruso, A.C. Intestinal permeability in patients with adverse reactions to food. Dig. Liver Dis. 2006, 38, 732-736. 
33. Song, D.J.; Cho, J.Y.; Miller, M. Anti-Siglec-F antibody inhibits oral egg allergen induced intestinal eosinophilic inflammation in a mouse model. Clin. Immunol. 2009, 131, 157-169.

34. Perrier, C.; Corthésy, B. Gut permeability and food allergies. Clin. Exp. Allergy 2011, 41, 20-28.

35. Hidalgo, I.J.; Raub, T.J.; Borchardt, R.T. Characterization of the human colon carcinoma cell line (Caco-2) as a model system for intestinal epithelial permeability. Gastroenterology 1989, 96, 736-749.

36. Wilson, G.; Hassan, I.F.; Dix, C.J.; Williamson, R.; Shah, R.; Mackey, M.; Artursson, P. Transport and permeability properties of human Caco-2 cells: An in vitro model of the intestinal epithelial cell barrier. J. Control Release 1990, 11, 25-40.

37. Pellegrina, C.D.; Rizzi, C.; Mosconi, S.; Zoccatelli, G.; Peruffo, A.; Chignola, R. Plant lectin as carriers for oral drugs: Is wheat germ agglutinin a suitable candidate? Toxicol. Appl. Pharm. 2005, 207, 170-178.

38. Xu, J.; Zhou, A.; Wang, Z.; Ai, D. Effects of glycinin and $\beta$-conglycinin on integrity and immune responses of mouse intestinal epithelial cells. J. Anim. Plant Sci. 2010, 20, 170-174.

39. Kenworthy, R. Observations on the effects of weaning in the young pigs: Clinical and histopathological studies of intestinal function and morphology. Res. Vet. Sci. 1976, 21, 69-75.

40. Bates, J.M.; Akerlund, J.; Mittge, E.; Guillemin, K. Intestinal alkaline phosphatase detoxifies lipopolysaccharide and prevents inflammation in zebrafish in response to the gut microbiota. Cell Host Microbe 2007, 2, 371-382.

41. Geddes, K.; Philpott, D.J. A new role for intestinal alkaline phosphatase in gut barrier maintenance. Gastroenterology 2008, 135, 8-12.

42. Yosbida, Y.; Ban, Y.; Kinosbita, S. Tight junction transmembrane protein claudin subtype expression and distribution in human corneal and conjunctival epithelium. Investig. Ophthalmol. Vis. Sci. 2009, 50, 2103-2108.

43. Yu, A.S.; McCarthy, K.M.; Francis, S.A.; McCormack, J.M.; Lai, J.; Rogers, R.A.; Lynch, R.D.; Schneeberger, E.E. Knockdown of occludin expression leads to diverse phenotypic alterations in epithelial cells. Am. J. Physiol. Cell Physiol. 2005, 288, C1231-C1241.

44. Zhao, J.H.; Wang, J.H.; Dong, L.; Shi, H.; Wang, Z.; Ding, H.; Shi, H.; Lu, X. A protease inhibitor against acute stress-induced visceral hypersensitivity and paracellular permeability in rats. Eur. J. Pharmacol. 2011, 654, 289-294.

45. Groschwitz, K.R.; Hogan, S.P. Intestinal barrier function: Molecular regulation and disease pathogenesis. J. Allergy Clin. Immunol. 2009, 124, 3-20.

46. Setsuko, I.; Fumio, Y. Determination of glycinin and $\beta$-conglycinin in soybean protein by immunological methods. Agric. Food Chem. 1987, 35, 200-205.

(C) 2014 by the authors; licensee MDPI, Basel, Switzerland. This article is an open access article distributed under the terms and conditions of the Creative Commons Attribution license (http://creativecommons.org/licenses/by/3.0/). 